\title{
Evidence base in health promotion: why bother?
}

\author{
Dr. Bury is presently director of the group "Development and Perspectives" for the Directorate of Health of the canton \\ of Geneva. The group is especially in charge of providing evidence base for policy decisions. He was formerly in charge of \\ training and research policy in public health at WHO EURO and later director of the Association of Schools of Public Health \\ in Europe
}

Nowadays, just about everyone is referring to "evidence base". The health promoter, because he or she wants to be funded, and funding is more and more going to project proposals based on evidence. The policy-maker, because of the critics asking for the "evidence", from colleagues in government, from his or her own political party as well as from the opposition, from the administration, from media, and so forth. Beyond the quest for legitimate accountability, it also relates to an internal, personal quest for increased professional satisfaction. But then comes the issue to really bother about: what is the relevant evidence that really helps to improve practices?

I will not try to provide "the answer" to such a question but to raise some of the elements to take into appropriate consideration.

In a recent interview about health promotion effectiveness, McMurtry (2002), a former Canadian vice-minister of health, stressed that there are two components of an evidence base that are critical for health promotion efforts: "The first is evidence that characterises the linkages between the determinants of health and health status... But it says little about the effectiveness of interventions... [which is] the second crucial component of the evidence base. While we've been reasonably successful at generating evidence for the first component, we've had more difficulty with the evidence of effectiveness." Recently, Macintyre (2003) made similar remarks concerning the UK context.

So what is evidence? The term evidence carries a connotation of certainty; it is the way to conclude "beyond a shadow of doubt" that something has occurred or is true. It is especially associated (at least in English) to the "evidence to be used in judicial proceedings" (Fielding 2003). It is too often equated to "data" or "facts" as if these were equivalent to reality as opposed to beliefs or opinions. "Data" are only one expression of observed or reported reality. "Evidence" depends on the tools and grids for analysis used in observations, the reliability and validity of the analyses, and the range of interpretation that is plausible. "Evidence" is inevitably relative, and this "fact" is easily forgotten in the daily, often intense disputes among interested parties discussing different intervention options in health promotion.

How may this differ from traditional evidence-based medicine approaches? Rather than criteria essentially relying on the relative "strength" of the research design, degrees of replicability of findings in experiments where potential biases are reduced or made explicit (with the optimal model being the randomized clinical trial (RCT)), within health promotion, a much broader view on evidence is required, as many authors have argued including those quoted here.

This expansion will avoid reducing social phenomena to the sum of individual characteristics. Furthermore, this broader view may avoid basing all inferences on artificial, experimental situations. For example, isolating groups from one another in the same community is at the expense of altering the natural environment or creating artificial barriers to prevent "contamination" during the usually long study period. Such conditions may not provide "evidence" that is generalisable to real life. Along these lines, the US Task Force on Community Preventive Services (see McQueen 2001) has noted that population-based prevention strategies frequently are multiple component, complex, and that randomised controlled trials may not be feasible or desirable to evaluate the effectiveness of community interventions (see Perkins et al. 1999).

Medicine is primarily a social and psychological practice. Health promotion is even more so. The search for "evidence" 
should use criteria applicable to human sciences rather than to how cells behave, as it is still too often the case in medicine.

Moreover, at the heart of health promotion are interdisciplinary approaches dealing with contextualisation and complexity. These two perspectives are reflected in the traditional opposition in evaluation between mechanistic and system types of evaluation.

Rather than resurrecting the old and inadequate debate between quantitative and qualitative studies, what matters is the epistemological assumptions behind the studies, be the studies quantitative, qualitative or a combination.

McQueen and Anderson (2001) argue that "the underlying epistemological basis for health promotion is not experimental science but social and behavioural sciences". I consider that the adherence to a positivist or a constructivist view of reality makes quite a difference in what will be considered relevant evidence.

At minimum, it is well established in social sciences that the observer becomes a participant and the human factor is often unidentified and or seen as difficult to control, replicate, or report on. Yet these observations have been taken into account in studies on leaders' roles in political sciences since a while (Grindle \& Thomas 1991).

In health promotion the ideal is to enlist a full participation of the client, beneficiary or citizen on an equal footing as coproducer of the process and moreover of the outcomes. In his Cochrane lecture at the Society for Social Medicine meeting in 1997, Hart argued that the advocates of evidence based medicine "accept uncritically a de-socialised definition of science ... and ignore the multiple nature of most clinical problems, as well as the complexity of social problems within which clinical problems arise and have to be solved." He argued that there is a need to work within a different paradigm based on a socialised definition of science. Hart's position is that a major part of the context of care, namely the patient's knowledge and experience, tends to be lost in the traditional efforts to search for an evidence-based medicine.

I stressed elsewhere (Bury 2000) the need to rely equally on diverse programme evaluations, especially when they have been well designed, repeated, and using different perspectives and tools, and provide the basis for good "cumulative evidence". This is the current trend in systematic reviews and research synthesis. One assumption is that diverse independent evaluations may capture the whole truth, including what is relevant more than a couple of RCTs (both may be needed).

This shift has contributed to the UK Health Development Agency to adopt a more balanced and inclusive approach to what makes up the evidence base by stating that "it is important to map the full range of different types of evidence $a b$ out what works, from the results of a RCT, to government guidance, expert consensus and more innovative types of research ..." (www.hda-online.org.uk)

Another issue recently on the agenda is the consequences of the pyramid of studies done, published, identified, retrieved, selected, obtained, analysed and then actually included in research syntheses. Selection biases are numerous: the most commonly cited are studies written up in English, conducted by Anglophones, referenced within Medline or ISI, and based on RCT study design. Are we sure at the end of the process to retain the best studies?

The demand and supply of "relevant" evidence to all actors and institutions, including the public, is the challenge that we do have to bother about.

The issue may be not so much what is right but what is good: not so much what is the true evidence than what is the relevant evidence.

Jacques A. Bury

\section{References}

Bury JA (2000). Evaluation: a key tool for improvement? In: European Monitoring Center for Drugs and Drug Addiction, ed. Evaluation: a key tool for improving drug prevention. Luxembourg: Office for Official Publications of the European Communities: 25-32.

Fielding JE (2003). Foreword. In: Brownson RC, et al. ed. Evidence - based public health. New York: OUP.

Grindle MS, Thomas JW (1991). Public choices and policy change: the political economy of reform in developing countries. Baltimore: Johns Hopkins University Press.
Hart J (1997). What evidence do we need for evidence-based medicine? J Epidemiol Community Health 51: 623-9.

Macintyre S (2003). Evidence-based policy making. BMJ 326: 5-6.

McMurtry R (2002). Health promotion effectiveness: health policy research. Bulletin Health Canada 1(3).

McQueen D, Anderson L (2001). What counts as evidence? In: Rootman I, Goodstadt M, Hyndman B, et al., eds. Evaluation in health promotion: principles and perspectives. Copenhagen: World Health Organization.
Perkins E, Simnett I, Wright L, eds. (1999). Evidence-based health promotion. New York: J. Wiley and Sons.

Address for correspondence

Dr. Jacques A. Bury

Fondation du Devenir

Directeur, Cellule Développement et Perspectives auprès de la Direction Générale de la Santé

20 rue des Caroubiers

CH-1227 Carouge

Tel. :+ 41228271956

Fax : +41 228271951

e-mail : jacques.bury.d-p@fdd.org 